\title{
Can Countries with Severe Labor Market Frictions Gain from Globalization?
}

\author{
Wolf-Heimo Grieben*
}

\begin{abstract}
The interaction between increased Southern trade integration (globalization) and labor market frictions is analyzed in a dynamic general-equilibrium North-South nonscale growth model with endogenous Northern innovation and endogenous Southern imitation. The qualitative employment, growth, and relative-wage effects of globalization are shown to depend crucially on the degree of Northern labor market frictions. I demonstrate that only Northern countries with particularly large labor market adjustment costs for both firms and workers benefit from globalization in terms of permanently lower unemployment, temporarily faster growth, and permanently higher wages. This is because of the resulting general-equilibrium feedback effects of Northern labor market frictions that deter Southern imitation incentives. The result does not imply the recommendation to increase Northern labor market rigidities, but it challenges the common belief that labor market flexibility helps Northern countries to better adjust to the "globalization threat" coming from the South.
\end{abstract}

\section{Introduction}

Does labor market flexibility help Northern industrialized countries to benefit more-or to be hurt less-from globalization? The answer will depend on how we define the terms "labor market flexibility," "benefit," and "globalization." A standard textbook argument says that trade liberalization is unambiguously beneficial for the welfare of countries if, and only if, factor (and product) prices are sufficiently flexible (e.g. Kenen, 2000, p. 203: "Free trade can reduce economic welfare when the real wage is rigid"). A similar point is made by Sinn (2004), and this will not be disputed here. In the model of this paper, I assume completely flexible wages but allow for adjustment costs for firms and workers following a globalization shock that requires a reallocation of labor in the North. Firms face closing-down or firing costs, and laid-off workers do not find immediately a new job in a different industry. It seems to be commonly accepted that even under flexible factor and goods prices, these adjustment costs result unambiguously in harmful globalization effects. This standard hypothesis- to be challenged by this paper-is reflected in, for example, Arnold (2002), Angrist and Kugler (2003), and Helpman and Itskhoki (2008). ${ }^{1}$

I do not analyze static welfare effects of trade liberalization but employment and growth effects of the entry of a large Southern developing country like China or India into the world free-trade market (i.e. increased Southern trade integration), which is modeled as an increase in the relative Southern population size. ${ }^{2}$ The issue in this paper

\footnotetext{
* Grieben: University of Konstanz, Universitaetsstr. 10, PO Box 146, 78457 Konstanz, Germany. Tel: +497531-88-5192; Fax: +49-7531-88-4558; E-mail: heimo.grieben@uni-konstanz.de. For valuable comments and suggestions, I thank Lutz Arnold, Pietro Peretto, Fuat Şener, two anonymous referees, the research group "Heterogeneous Labor" (Konstanz, Mannheim), and participants of the conferences Minerva-DEGIT in Jerusalem, 2006, EEA-ESEM in Vienna, 2006, and VfS in Bayreuth, 2006. This work was supported by a grant from the Ministry of Science, Research, and the Arts of Baden-Wuerttemberg, Germany (Az: 21-655.042-52/1). The usual disclaimer applies.
} 
then is to show how the qualitative effects of this type of globalization on R\&D-driven growth and unemployment in the North depend on the degree of Northern labor market frictions, as measured by firing costs and a unified job-finding rate. The framework used to tackle these issues is a two-country (North-South) quality ladder model, which features a Vernon-type product cycle, neo-Schumpeterian nonscale growth with endogenous Northern innovation and endogenous Southern imitation.

I argue that these labor market adjustment costs will affect the endogenous globalization pressure (its imitation rate) from a Southern developing country. I show that accounting for these feedback effects from Northern labor market frictions to the Southern imitation incentives can qualitatively change the effects of globalization in general equilibrium. Hence, the central new feature of this paper is that it introduces a theoretical link from labor market frictions in the North to the globalization pressure coming from the South, and the main new finding is that, contrary to standard belief, Northern countries with significant labor market frictions for both firms and workers will benefit from globalization in terms of growth and employment. ${ }^{3}$

More specifically, I derive critical threshold levels for firing costs and the job-finding rate and show that if both measures for labor market adjustment costs indicate strong inflexibility, Northern consumers experience a "double dividend" from globalization: they benefit from globalization in terms of employment and quality growth. This is no longer true for countries with either asymmetric (i.e. only one measure for labor market adjustment costs indicates strong inflexibility) or no significant labor market adjustment costs. Hence, my model does not support the popular view, as exemplified by Arnold (2002), that consumers in developed countries with significant labor market frictions necessarily benefit less from globalization in terms of employment and growth than consumers in developed countries with more flexible labor markets. ${ }^{4}$

My model differs from Arnold (2002) in three important respects. First, I analyze a semi-endogenous nonscale growth model (with vertical innovations), whereas his model belongs to the first generation of endogenous growth models (with horizontal innovations) and hence features scale effects. As a consequence, in my model, growth effects of globalization will only be temporary. Secondly, I fully model the consumption and production side of the Southern economy, and thereby I derive the Southern imitation rate endogenously. As a consequence, instead of analyzing directly the effects of an increase in the Southern imitation rate, I look at the effects of increased Southern trade integration which may result in increasing Southern imitation. The main finding of a "double dividend" for the North results precisely from the fact that the severe Northern labor market frictions cause a decrease in Southern imitation as a result of globalization, which reduces Northern unemployment, while Northern R\&D incentives are improved. Thirdly, I introduce firing costs as a second labor market imperfection. As a consequence, I am able to analyze the interplay of two different labor market imperfections.

My model adopts the basic framework from Dinopoulos and Segerstrom (2007, DS hereafter) who in turn build on Grossman and Helpman (1991). DS develop a NorthSouth neo-Schumpeterian product-lifecycle model with nonscale (semi-endogenous) growth driven by endogenous Northern innovation, and with endogenous Southern imitation. Globalization takes the form of the entry of a large Southern developing country (the newly industrialized South) like China into the world free-trade markets, where new Southern firms compete with the established Northern firms on the markets for qualitatively diversified consumer goods. The entry of the South is technically modeled as a discontinuous rise in the Southern population size. On the one hand, this form of globalization improves incentives for Northern quality follower firms to engage 
in $R \& D$ by raising the market size to which these firms (once they become quality leaders) can sell their products. On the other hand, a more populous South can invest more in imitative $R \& D$, hence this form of globalization "steals the business" of established Northern quality leader firms whose products are driven from the world market since they are imitated at lower wage costs by new Southern quality leaders. With intersectoral mobility of workers in perfectly flexible labor markets, the flow of production jobs from the North to the low-wage South implies that more Northern workers are available for doing R\&D in quality follower firms, which results in a temporary rise in the Northern growth rate above its steady-state level. I generalize the model of DS (2007) by introducing firing costs and frictional unemployment.

\section{The Model}

\section{Household Behavior}

In both countries, there is a fixed number of households forming a dynastic family whose individual members have an infinite lifetime. The number of household members is growing at a common rate $n>0$, and each household member supplies inelastically one unit of labor. There is full employment in the South, hence the Southern labor force at time $t$ is given by $\bar{L}_{S, t}=L_{S, 0} e^{n t}$. Owing to a labor market imperfection to be discussed later, there is unemployment in the North, and its labor force is given by $L_{N, t}=\left(1-u_{t}\right) L_{N, 0} e^{n t}=\left(1-u_{t}\right) \bar{L}_{N, l}$, where $\bar{L}_{N, t}$ denotes the exogenous size of total Northern population at time $t$, and $u_{t}$ is the endogenous Northern unemployment rate at time $t$. I allow for different initial population sizes, $L_{S, 0} \neq L_{N, 0}$. Households in North and South share preferences and maximize the discounted lifetime utility

$$
Z \equiv \int_{0}^{\infty} e^{-(\rho-n) t} \ln z_{t} d t
$$

with constant time-preference rate $\rho>n$ and the individual instantaneous CES-utility function

$$
z_{t}=\left\{\int_{0}^{1}\left[\sum_{j} \lambda^{\frac{j}{\sigma-1}} d(j, \omega, t)\right]^{(\sigma-1) / \sigma} d \omega\right\}^{\sigma /(\sigma-1)} .
$$

Equation (2) is a quality-augmented Dixit-Stiglitz consumption index, where $d(j, \omega, t)$ is the quantity of vertically differentiated goods with $j$ quality improvements in industry $\omega$ consumed at time $t, \lambda>1$ is the size of each quality improvement in the case of successful innovation, and $\sigma>1$ is the constant elasticity of substitution between products across industries. There is a continuum of industries defined over the unit interval, $\omega \in[0,1]$. A standard result in neo-Schumpeterian growth theory is that within industries, consumers buy only products with the lowest quality-adjusted price, hence in (2), the sum over qualities $j$ can be deleted. Across industries, consumers solve the static optimization problem

$$
\max _{d(\cdot)} \int_{0}^{1}\left[\lambda^{\frac{j(\omega, t)}{\sigma-1}} d(\omega, t)\right]^{(\sigma-1) / \sigma} d \omega \quad \text { subject to } \quad \int_{0}^{1} p(\omega, t) d(\omega, t) d \omega=c_{t} .
$$

In (3), $t$ is fixed, $d(\omega, t)$ is the individual's quantity demanded of the product with the lowest quality-adjusted price in industry $\omega$ at time $t, j(\omega, t)$ is the quality index, $p(\omega, t)$ is the corresponding price of this good, and $c_{t}$ is the consumption expenditure at time $t$. The solution of (3) yields the individual's consumption demand function 


$$
d(\omega, t)=\frac{q(\omega, t) p(\omega, t)^{-\sigma} c_{t}}{\int_{0}^{1} q(\omega, t) p(\omega, t)^{1-\sigma} d \omega}
$$

where $q(\omega, t) \equiv \lambda^{j(\omega, t)}$ measures the product quality in industry $\omega$ at time $t$. The intertemporal budget constraint of a household in the North and the South is of the form

$$
\dot{A_{t}}=r_{t} A_{t}+W_{t}-c_{t}-n A_{t},
$$

where $A_{t}$ is per-capita asset holdings at time $t, r_{t}$ is the market interest rate at time $t$, and $W_{t}$ is the individual's expected wage income at time $t$. Maximizing (1) subject to (2), (4), and (5) yields the usual intertemporal Euler equation

$$
\dot{c}_{t} / c_{t}=r_{t}-\rho .
$$

In both countries, there are two activities, production and $\mathrm{R} \& \mathrm{D}$, and labor is perfectly mobile across industries and between activities, but immobile between countries. Unemployment affects only Northern production workers: once there is Southern imitation and the corresponding industry relocates the production site to the South with lower wage costs (wage rates are $w_{S} \equiv 1<w_{N}$ ), they are laid off while R\&D workers always stay employed. There is perfect income insurance among members of the same household (they share income evenly as in DS, 1999, p. 454, and in Şener, 2001, p. 125), and across employment types within the North. I assume that immediately when born, each Northern individual still does not know whether he will end up as a production or as an R\&D worker, and hence all simultaneously-born individuals are willing to insure each other against the unemployment risk. The premium for this perfect insurance equals $u w_{N}$, hence the net expected wage rate of all workers is $(1-u) w_{N}$, while the gross wage rate of all workers (which matters for marginal production and R\&D costs in the North) is $w_{N}$. The assumption of perfectly flexible, competitively determined wage rates imply that I abstract from any wage-bargaining power of workers. The same assumptions are implicitly made in Arnold (2002).

\section{Product Markets, Innovation, and Imitation}

The industry side of my model is almost identical to DS (2007). In any industry $\omega \in[0$, 1], irrespective of the quality level of the corresponding goods, output equals labor input: $Y_{N}=L_{N}^{Y}$ in the North and $Y_{S}=L_{S}^{Y}$ in the South. The R\&D process specified below results in a unique quality leader in each industry who is protected by an exclusive patent on his production technology, and who charges an unconstrained monopoly price derived below. This patent expires in the case of two events: either another innovation occurs in the same industry by a Northern firm, or the leading technology is imitated by a Southern firm producing at lower marginal costs $w_{S} \equiv 1<w_{N}$. In both cases, the previous incumbent immediately leaves the market and cannot credibly threaten to re-enter (since he would make zero profits in an equilibrium with Bertrand price competition). In the North, the current quality leader maximizes global monopoly profits $\pi_{N}=\left(p_{N}-w_{N}\right)\left(d_{N} L_{N}+d_{S} \bar{L}_{S}\right)$ with respect to $p_{N}$, where Northern and Southern demand functions $d_{N}$ and $d_{S}$ are given by (4), respectively. ${ }^{5}$ Provided $\sigma>1$, it results the unconstraint monopoly price $p_{N}=[\sigma /(\sigma-1)] w_{N}$ in each industry with a Northern quality leader. Similarly, the successful Southern imitating firm maximizes global monopoly profits $\pi_{S}=\left(p_{S}-w_{S}\right)\left(d_{N} L_{N}+d_{S} \bar{L}_{S}\right)$ with respect to $p_{S}$, which results in the monopoly price $p_{S}=[\sigma /(\sigma-1)] w_{S}$ in each industry with a Southern quality leader. 
$E \equiv c_{N} N_{N}+c_{S} \bar{L}_{S}$ is the global consumption expenditure, and $\bar{c}=E /\left(L_{N}+\bar{L}_{S}\right)$ is the global per-capita consumption expenditure. I follow the notation in DS (2007) by denoting $Q_{t} \equiv \int_{0}^{1} q(\omega, t) d \omega$ the average quality level across industries (some of which are producing in the North, some in the South) at time $t$. Then, from (4), the per-capita global demand for a Northern product with average quality level $Q$ is

$$
\bar{d}_{N, t}=\frac{Q_{t} \cdot p_{N, t}^{-\sigma} \bar{c}_{t}}{\int_{0}^{1} q(\omega, t) p(\omega, t)^{1-\sigma} d \omega},
$$

and the Southern equivalent $\bar{d}_{S}$ is found by simply replacing $p_{N}$ by $p_{S}$ in the numerator of (7). It follows that global monopoly profits of a Northern quality leader can be written as

$$
\pi_{N}(\omega)=\frac{w_{N}}{\sigma-1} \bar{d}_{N}\left(L_{N}+\bar{L}_{S}\right) \frac{q(\omega)}{Q}
$$

which is the product of profit margin, total market size, and goods quality relative to the average.

Now I consider Northern innovative and Southern imitative R\&D activities. The $R \& D$ production function of a Northern innovating firm in industry $\omega$ is

$$
I_{i}(\omega)=\eta_{I} L_{N, i}^{I} / q(\omega)
$$

where $I_{i}$ is a Poisson arrival rate, $\eta_{I}>0$ is an R\&D productivity parameter, and $L_{N, i}^{I}$ is labor input of firm $i$, with $\Sigma_{i} L_{N, i}^{I}=L_{N}^{I}$ being the total number of Northern R\&D workers. The quality level $q(\omega, t)=\lambda^{j(\omega, t)}$ in the denominator captures the idea that with rising product quality, further improvement becomes increasingly difficult since products become more complex. $R \& D$ returns are assumed to be distributed independently across firms, across industries, and over time; hence the industry-wide instantaneous probability of innovation is $I(\omega)=\eta_{I} L_{N}^{I} / q(\omega)$. Similarly, the Poisson arrival rate of a Southern imitating firm $j$ is defined as

$$
C_{j}(\omega)=\eta_{C} L_{S, j}^{C} / q(\omega),
$$

with $\mathrm{R} \& \mathrm{D}$ productivity parameter $\eta_{C}>0$, and $\Sigma_{j} L_{S, j}^{C}=L_{S}^{C}$ is the total number of Southern R\&D workers. $C(\omega)=\eta_{C} L_{S}^{C} / q(\omega)$ is the industry-wide instantaneous probability of imitation. R\&D difficulty of Southern copying is identical to Northern R\&D difficulty because the required technical knowledge for producing a particular quality of a given product is the same.

With $w_{N}>w_{S}>w_{N} / \lambda^{1 /(\sigma-1)}$, the successful Southern imitating firm replaces the previous Northern incumbent and serves the world market, and in the case of a further innovation, the new Northern quality leader replaces the previous Southern monopolist in turn. Contrary to DS (2007), I abstract from any trade costs. Denoting $m_{N}\left(m_{S}\right)$ the fraction of industries with a Northern (Southern) quality leader, in a steady state with constant $I$ and $C$, the flow of industries $\omega$ with a new Southern quality leader must equal the flow of industries with a new Northern quality leader, thus $m_{N} C=m_{S} I$. With $m_{N}+m_{S}=1$, it follows that $m_{N}=I /(I+C)$ and $m_{S}=C /(I+C)$.

Northern firms choose R\&D intensity $I_{i}$ to maximize expected benefits minus costs from engaging in R\&D: $v_{I}(\omega) I_{i}-\left(1-s_{R}\right) w_{N} L_{N, i}^{I}$, where $v_{I}(\omega)$ is the reward for innovating, and $s_{R} \geq 0$ is an R\&D subsidy. With free entry into R\&D races, optimal Northern $\mathrm{R} \& \mathrm{D}$ investment satisfies 


$$
v_{I}(\omega)=\left(1-s_{R}\right) w_{N} q(\omega) / \eta_{I}
$$

Since product quality $q(\omega)$ stays constant during an R\&D race, $v_{I}$ is also a constant, i.e. $\dot{v}_{I}=0$. The usual no-arbitrage condition on the world stock market equates the return from a completely diversified portfolio of the stocks of Northern R\&D firms and the safe interest rate for a riskless bond, where both assets are held for a time period $d t$ :

$$
\frac{\pi_{N}(\omega, t)}{v_{I}(\omega, t)} d t+\frac{\dot{v}_{I}(\omega, t)}{v_{I}(\omega, t)} d t(1-I d t-C d t)-\frac{v_{I}(\omega, t)+F(\omega, t)}{v_{I}(\omega, t)}(I+C) d t=r d t
$$

All terms are standard except for the third term on the left-hand side. I specify that in addition to suffering from full capital loss in the case of either further Northern innovation or Southern imitation, the previous Northern incumbent firm has to pay firing costs, defined as $F \equiv B v_{I}$ with $B>0$ being a constant, each time it is replaced from the goods market and thus is forced to dismiss its production workers. ${ }^{6}$ Firing costs are indexed to $v_{I}$ in order not to become negligible in the long run. Dividing (12) by $d t$, using $r_{t}=\rho$ and $\dot{v}_{I} / v_{I}=0$ gives the steady-state innovation reward

$$
v_{I}=\pi_{N} /[\rho+(1+B)(I+C)] .
$$

From (8), (11), and (13), I derive the Northern steady-state innovative $R \& D$ condition

$$
\frac{\left(1-s_{R}\right) x_{N}}{\eta_{I}}=\frac{\bar{d}_{N}\left[1+\left(\bar{L}_{S} / L_{N}\right)\right]}{(\sigma-1)[\rho+(1+B)(I+C)]},
$$

where $x_{N} \equiv Q / L_{N}$ is a measure for the relative R\&D difficulty. The left-hand side (right-hand side) shows the cost (expected discounted benefit) of innovating per Northern employed worker.

Similarly, Southern firms optimally choose R\&D intensity $C_{j}$ as to maximize expected benefits minus costs from engaging in R\&D: $v_{C}(\omega) C_{j}-w_{S} L_{S, j}^{C}$, where $v_{C}(\omega)$ is the reward for imitating. With free entry to $R \& D$ races, optimal Southern R\&D investment satisfies

$$
v_{C}(\omega)=w_{S} q(\omega) / \eta_{C}
$$

The Southern no-arbitrage equation equivalent to (12) is

$$
\frac{\pi_{S}(\omega, t)}{v_{C}(\omega, t)} d t+\frac{\dot{v}_{C}(\omega, t)}{v_{C}(\omega, t)} d t(1-I d t)-I d t=r d t
$$

where global monopoly profits of a Southern quality leader are

$$
\pi_{S}(\omega)=\frac{w_{S}}{\sigma-1} \bar{d}_{S}\left(L_{N}+\bar{L}_{S}\right) \frac{q(\omega)}{Q}
$$

similar to (8), with $\bar{d}_{S}=\bar{d}_{N}\left(p_{N} / p_{S}\right)^{\sigma}$. From (16), the steady-state reward for imitation is

$$
v_{C}=\pi_{S} /(\rho+I) \text {. }
$$

Then, from equations (15), (17), and (18), the Southern steady-state imitative $R \& D$ condition is 


$$
\frac{x_{N}}{\eta_{C}}=\frac{\bar{d}_{S}\left[1+\left(\bar{L}_{S} / L_{N}\right)\right]}{(\sigma-1)(\rho+I)} .
$$

As in (14), the left-hand side (right-hand side) shows the cost (expected discounted benefit) of imitating per Northern employed worker.

\section{Quality Dynamics and Labor Markets}

Before determining the labor market equilibrium for both countries, I need to derive (thereby reproducing results of DS, 2007) how product quality evolves in North and South, because this is closely related to the demand for production workers. From the definition $Q_{t} \equiv \int_{0}^{1} q(\omega, t) d \omega=\int_{0}^{1} \lambda^{j(\omega, t)} d \omega$, it follows

$$
\dot{Q}=\int_{0}^{1}\left[\lambda^{j(\omega)+1}-\lambda^{j(\omega)}\right] I d \omega=(\lambda-1) I \int_{0}^{1} \lambda^{j(\omega)} d \omega=(\lambda-1) I Q,
$$

since product quality jumps up from $\lambda^{j}$ to $\lambda^{j+1}$ with each innovation that occurs with constant instantaneous probability $I$. As is derived in DS (2007), a constant steadystate growth rate of Northern and Southern average product quality (defined as $Q_{N} / m_{N} \equiv \int_{m_{N}} q(\omega) d \omega / m_{N}$ and $\left.Q_{S} / m_{S} \equiv \int_{m_{S}} q(\omega) d \omega / m_{S}\right)$, requires equal growth rates $\dot{Q}_{N} / Q_{N}=\dot{Q}_{S} / Q_{S}$. Moreover, DS (2007) derive

$$
Q_{N}=\lambda I Q /(\lambda I+C) \text { and } Q_{S}=C Q /(\lambda I+C) .
$$

There is frictional unemployment similar to Arnold (2002; see his motivation on pp. 455-56). Northern production workers lose their jobs because of Southern imitation (which forces the Northern incumbent to shut down), and it takes time to re-enter the labor market. The unemployed production worker's instantaneous probability of re-entering the Northern labor market equals a constant $\beta>0$, which implies an expected duration $1 / \beta$ of unemployment. ${ }^{7}$ This means that Northern employment $L_{N}<\bar{L}_{N}$ follows the differential equation

$$
\dot{L}_{N}=\bar{L}_{N}(\beta u+n)-C L_{N}^{Y}
$$

Note two differences relative to Arnold (2002) with respect to (22): first, the imitation rate $C$ is endogenous here. Secondly, since I have positive population growth in this model but want to abstract from demographic unemployment, I make the simplifying assumption that all newly-born Northern individuals immediately become employed and only lose their job if production moves to the South after imitation occurred. As in Arnold (2002), Northern innovation in an industry with a Northern quality leader does not cause additional frictional unemployment since the new incumbent firm instantaneously offers an equal amount of $L_{N}^{Y}$-type jobs. This can be justified on two grounds: first, while Northern innovation implies intraindustry labor reallocation for production workers of the previous incumbent, Southern imitation requires interindustry labor reallocation. Arguably, adoption to the work in a different industry will produce more frictional unemployment than job switching within the same industry. Secondly, since this is a semi-endogenous growth model, the steady-state innovation rate will not be affected by globalization anyway.

Goods market clearing implies that global demand for a Northern product with average Northern quality must equal Northern supply of goods, hence 


$$
\bar{d}_{N} \frac{Q_{N}}{Q}\left(L_{N}+\bar{L}_{S}\right)=\bar{d}_{N} \frac{\lambda I}{\lambda I+C}\left(L_{N}+\bar{L}_{S}\right)=Y_{N}=L_{N}^{Y}
$$

with $\bar{d}_{N}$ given in (7). Equilibrium in the Northern labor market implies $(1-u) \bar{L}_{N}=L_{N}=L_{N}^{Y}+L_{N}^{I}$. Using this, $L_{N}^{I}=I Q / \eta_{I}$ from aggregating (9) over all industries $\omega$ (since innovative $R \& D$ takes place in both industries with a Northern and a Southern quality leader), and (23) give

$$
1=\bar{d}_{N} \frac{\lambda I}{\lambda I+C} \frac{L_{N}+\bar{L}_{S}}{L_{N}}+\frac{I x_{N}}{\eta_{I}}
$$

as the steady-state equilibrium condition for the Northern labor market. Since the first term on the right-hand side of (24) is constant in a steady state, $x_{N}$ must also be a constant. This in turn requires $\dot{Q} / Q=\dot{L}_{N} / L_{N}=\dot{\bar{L}}_{N} / \bar{L}_{N}=n$, which by use of (20) pins down the steady-state innovation rate:

$$
I=n /(\lambda-1)
$$

Similar to (23), Southern goods market clearing requires

$$
\bar{d}_{S} \frac{Q_{S}}{Q}\left(L_{N}+\bar{L}_{S}\right)=\bar{d}_{S} \frac{C}{\lambda I+C}\left(L_{N}+\bar{L}_{S}\right)=Y_{S}=L_{S}^{Y}
$$

Equilibrium in the Southern labor market implies $L_{S}=\bar{L}_{S}=L_{S}^{Y}+L_{S}^{C}$. Using $L_{S}^{C}=C Q_{N} / \eta_{C}$ from aggregating (10) over the measure $m_{N}$ of all industries with a Northern quality leader (because copying takes place only there), (21), (26), and the definition $x \equiv Q / L_{N}$ give

$$
1=\frac{C}{(\lambda I+C) \bar{L}_{S}}\left[\bar{d}_{S}\left(L_{N}+\bar{L}_{S}\right)+\frac{\lambda I x_{N} L_{N}}{\eta_{C}}\right]
$$

as the steady-state equilibrium condition for the Southern labor market.

\section{Steady-State Equilibrium}

I derive the steady-state equilibrium with the constant $I, C, x_{N}, \bar{c}, E, r=\rho, w_{N}, w_{S} \equiv 1$, and with $L_{N}, L_{N}^{Y}, L_{N}^{I}, \bar{d}_{N}, \bar{d}_{S}$, and $Q$ all growing at the rate $n$. The equilibrium of DS (2007) is obtained as a special case with a perfectly flexible labor market $(\beta \rightarrow \infty)$ and no firing costs $(B=0)$.

Using in (22) the fact that Northern steady-state employment must grow at the rate of population growth $\left(\dot{L}_{N} / L_{N}=n\right)$, and $L_{N}=(1-u) \bar{L}_{N}$, solving that equation for $u$ yields

$$
u=C L_{N}^{Y} /\left[(\beta+n) \bar{L}_{N}\right] .
$$

Note that the steady-state unemployment rate depends positively on the proportion of production employment in total Northern population, $L_{N}^{Y} / \bar{L}_{N}$, since those jobs are vulnerable to Southern competition. Substituting for $L_{N}^{Y}$ in (28) from (23), using (14) to substitute for $\bar{d}_{N}$, and using $L_{N}=(1-u) \bar{L}_{N}$ again, finally yields

$$
u=\frac{1}{1+\frac{\eta_{I}(\lambda I+C)(\beta+n)}{\left(1-s_{R}\right) x_{N}(\sigma-1) C \lambda I[\rho+(1+B)(I+C)]}},
$$


which defines the Northern steady-state unemployment rate as a function of the endogenous variables $C$ and $x_{N}$, given $I=n /(\lambda-1)$ from (25). Obviously, $u$ increases in both the relative R\&D difficulty $x_{N}$ (since a higher $x_{N}$ reduces net benefits from innovating in (14), which implies that a larger proportion of Northern labor is employed in production where jobs are vulnerable to Southern imitation) and the Southern imitation rate $C$.

Next, by solving (14) for $\bar{d}_{N}$ and substituting this into (24), I derive the Northern steady-state condition as a function of the endogenous variables $C$ and $x_{N}$ :

$$
1=\frac{x_{N} I}{\eta_{I}}\left\{\frac{(\sigma-1) \lambda\left(1-s_{R}\right)[\rho+(1+B)(I+C)]}{\lambda I+C}+1\right\} .
$$

For $B=s_{R}=0$, (30) turns into the special case considered in DS (2007). Similarly, solving (19) for $\bar{d}_{S}$ and substituting this together with $L_{N}=(1-u) \bar{L}_{N}$ into (27) gives

$$
1=\frac{C x_{N}(1-u) \bar{L}_{N}}{(\lambda I+C) \bar{L}_{S} \eta_{C}}[(\sigma-1)(\rho+I)+\lambda I]
$$

Setting $u=0$ (i.e. $\beta \rightarrow \infty$ ) gives the special case considered in DS (2007). Substituting for $u$ from (29) finally yields the Southern steady-state condition as a function of $C$ and $x_{N}$ :

$$
1=\frac{\bar{L}_{N}[(\sigma-1)(\rho+I)+\lambda I]}{\bar{L}_{S} \eta_{C}\left\{\frac{\lambda I}{C x_{N}}+\frac{1}{x_{N}}+\frac{\left(1-s_{R}\right)(\sigma-1) \lambda I[\rho+(1+B)(I+C)]}{\eta_{I}(\beta+n)}\right\}} .
$$

In order to derive the unique steady-state equilibrium of the model graphically, I discuss the slope of the two curves defined by (30) and (31). Contrary to DS (2007), the slope of the Southern steady-state curve (31) is no longer unambiguously negative. The right-hand side of (31) is increasing in $x_{N}$, while the right-hand side of (31) is increasing in $C$ if, and only if,

$$
\beta>\frac{C^{2} x_{N}\left(1-s_{R}\right)(\sigma-1)(1+B)}{\eta_{I}}-n \equiv \beta^{\text {crit }}
$$

is fulfilled, i.e. the Northern labor market must be sufficiently flexible as captured by the parameter $\beta$. Hence with $\beta>\beta^{\text {crit }}\left(\beta<\beta^{\text {crit }}\right)$, after a rise in $x_{N}$, a decrease (increase) in $C$ is required to restore equilibrium in the South, so the curve for the Southern steadystate condition (31) is downward (upward) sloping in $\left(x_{N}, C\right)$-space, whereas for $\beta=\beta^{\text {crit }}$ it is vertical. With $\beta>\beta^{\text {crit }}$, the interpretation of the negative slope is the same as in DS (2007). An increase in the Southern imitation rate $C$ raises both the proportion of industries $m_{S}$ with a Southern quality leader serving the world market (which increases production labor demand $L_{S}^{Y}$ ) and the Southern R\&D labor demand $L_{S}^{C}$. For given labor supply, this requires a decrease in $x_{N}$ to ensure equilibrium on the Southern labor market. The decrease in $x_{N}$ reduces both $\mathrm{R} \& \mathrm{D}$ labor needed to maintain a given imitation rate $C$ and $\bar{d}_{S}$ (and thus $L_{S}^{Y}$ ) needed for Southern monopolists to break even; see (19). With $\beta<\beta^{\text {crit }}$, an increase in $C$ still raises $m_{s}$ and-ceteris paribus-the demand for Southern R\&D workers. However, the resulting decrease in Northern employment $L_{N}$ is particularly strong, which has two opposite effects on Southern labor demand: it reduces $L_{S}^{Y}$ but increases $L_{S}^{C}$ since Southern R\&D benefits per Northern employed worker increase; see (19). The effect on $L_{S}^{Y}$ dominates, hence $x_{N}$ must increase in order to clear the Southern labor market. 
The critical value $\beta^{\text {crit }}$ is increasing in all those variables and parameters that ceteris paribus also raise the steady-state unemployment rate given in (29): the larger $C, x_{N}, \sigma$, or $B$, and the lower $s_{R}, \eta_{I}$, or $n$, the higher is $u$ for any given $\beta .^{8}$ This means that if Northern unemployment is relatively high for a given value of $\beta$, the critical level $\beta^{\text {crit }}$ of Northern labor market flexibility at which the Southern steady-state curve becomes vertical is larger, i.e. an increase in $C$ is more "likely" to require an increase in $x_{N}$ in order to clear the Southern labor market.

Again contrary to DS (2007), the slope of the Northern steady-state condition (30) is no longer unambiguously positive. To see this, first observe that the right-hand side of (30) is increasing in $x_{N}$. Then, differentiate the right-hand side of (30) with respect to $C$, use $I=n /(\lambda-1)$ and find that the right-hand side of (30) decreases in $C$ - thus, the curve for the Northern steady-state condition is upward sloping in $\left(x_{N}, C\right)$-spaceif, and only if,

$$
B<(\rho-n) / n \equiv B^{\text {crit }}>0,
$$

whereas for sufficiently large firing costs $B>B^{\text {crit }}\left(B=B^{\text {crit }}\right)$ it is downward sloping (vertical).

To interpret the slope of the Northern steady-state curve, I note that DS (2007) and this model share two steady-state effects of an increase in $C$ on the Northern economy. First, with more Southern copying, the fraction $m_{N}$ of industries with a Northern quality leader declines, which means that fewer production workers $L_{N}^{Y}$ are needed. For a given supply of workers and no unemployment, these former production workers must be absorbed as $\mathrm{R} \& \mathrm{D}$ workers, and rising $\mathrm{R} \& \mathrm{D}$ employment implies a temporary increase in the innovation rate, which results in a permanently higher level of relative R\&D difficulty $x_{N}$. Thus, the first effect contributes to a positive slope of the curve for (30). Second, more Southern copying means a higher effective discount rate on benefits from innovating in (14), which requires a larger market size for given $x_{N}$ such that the innovating firms break even. Given the total number of consumers $L_{N}+\bar{L}_{S}$, this requires an increase in global demand for Northern products with average quality $\bar{d}_{N}$. Hence, output and demand for production workers $L_{N}^{Y}$ must increase, which works toward a lower level of $x_{N}$. Thus, the second effect contributes to a negative slope of the curve for (30). With $B=0$ and $\beta \rightarrow \infty$, the first effect dominates the second, and the Northern steady-state curve is positively sloped.

In my extended version of the model there are two additional steady-state effects of an increase in $C$ on the Northern economy. The third effect-which I term the "firingcost effect" for later reference-comes from the fact that more Southern copying means more dismissals of production workers in the North, which implies higher expected firing cost payments $B v_{l} C$ (obviously, the marginal impact of this effect will be the stronger the higher $B$ is). This reduces the benefit from innovating in (14). Given $x_{N}$, this again requires an increase in $\bar{d}_{N}$ such that the innovating firms break even, hence an increase in $L_{N}^{Y}$ is needed. Since for given $L_{N}$ this means a required decline in R\&D employment $L_{N}^{I}$, the third effect works toward a decline in relative R\&D difficulty $x_{N}$ after a rise in Southern copying $C$ (and hence toward a negative slope of the Northern steady-state curve). The interpretation of the expression for $B^{\text {crit }}$ in (33) is now straightforward. First, the larger the interest rate $r=\rho$, the more are expected firing costs discounted, which means that they become less relevant in determining the change of Northern R\&D incentives if the rate of Southern copying $C$ increases, hence the critical level $B^{\text {crit }}$ at which the Northern steady-state curve becomes vertical is larger. That is, an 

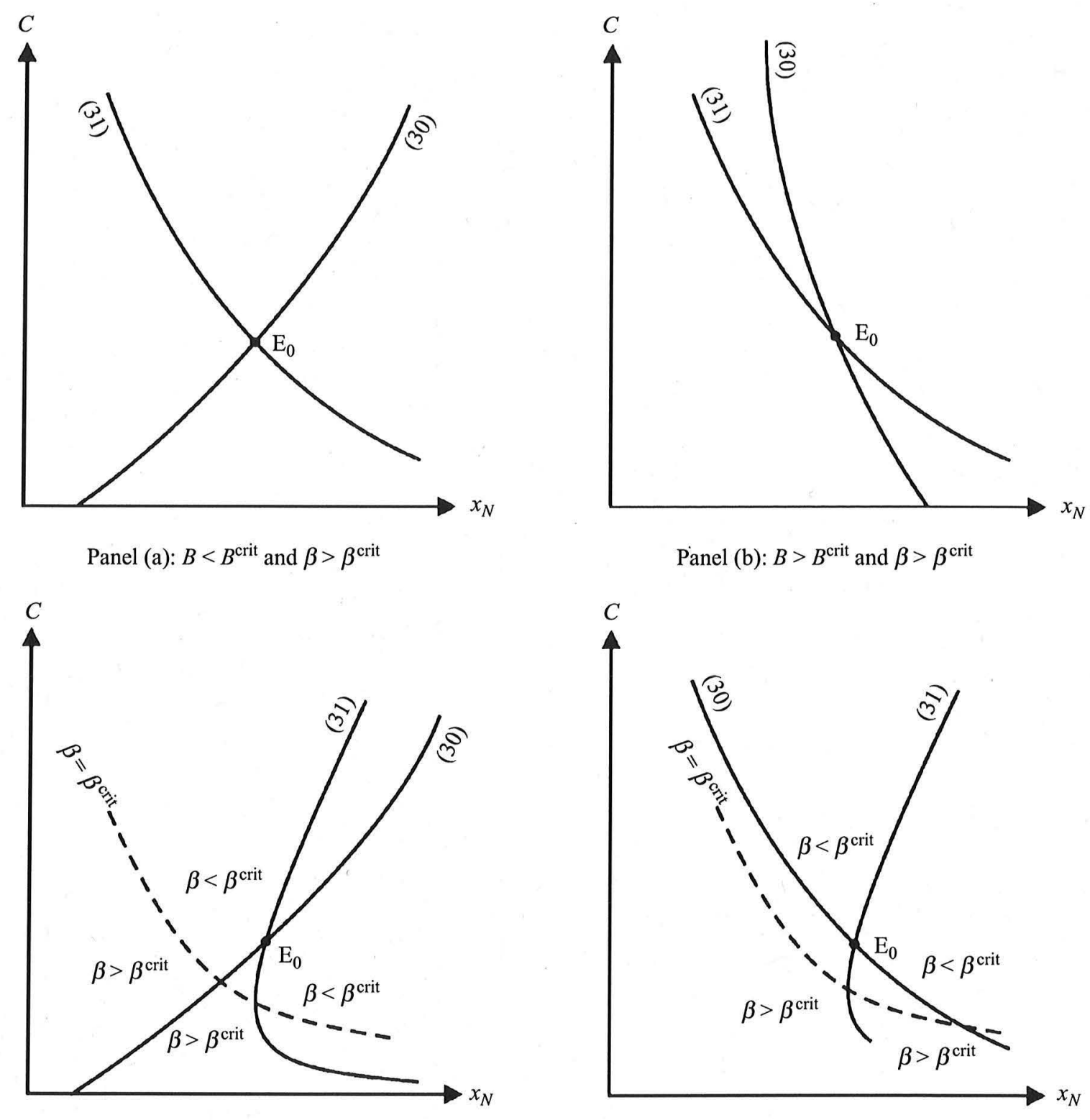

Panel (b): $B>B^{\text {crit }}$ and $\beta>\beta^{\text {crit }}$

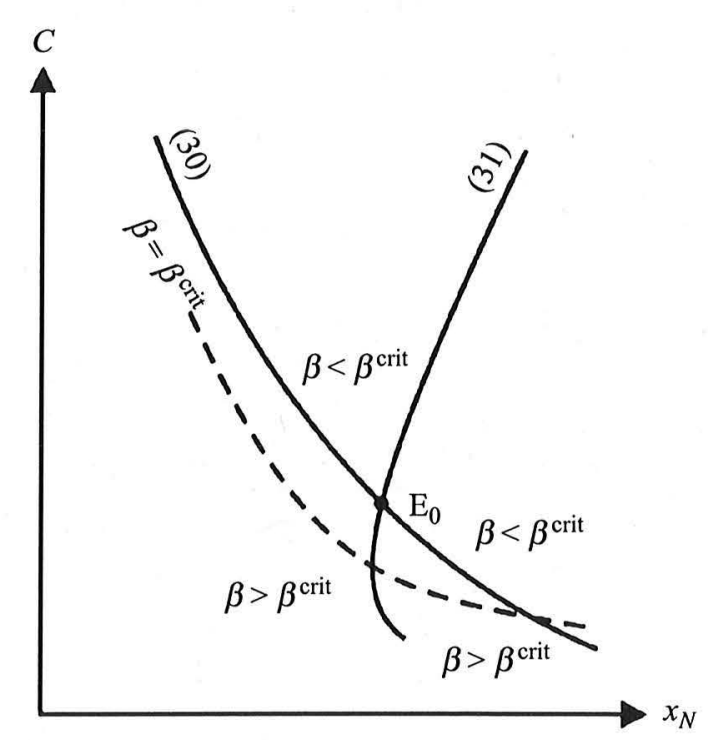

Panel (c): $B<B^{\text {crit }}$ and $\beta<\beta^{\text {crit }}$

Panel (d): $B>B^{\text {crit }}$ and $\beta<\beta^{\text {crit }}$

Figure 1. Steady-State Equilibrium

increase in $C$ is less "likely" to require a decline in $x_{N}$ in order to clear the Northern labor market. Secondly, $B^{\text {crit }}$ declines with rising $n$ since $I=n /(\lambda-1)$ rises with $n$, and this increases expected firing cost payments (and hence the effective discount rate on the right-hand side of (14)), which raises the relevance of firing costs for Northern $\mathrm{R} \& \mathrm{D}$ incentives.

Finally, the fourth effect of an increase in $C$ works via a reduction of Northern employment. An increase in Southern copying raises the labor market turnover in the North, which for given expected length of unemployment spells $1 / \beta$ implies a decline in total Northern employment $L_{N}$. This increases the expected discounted benefit from innovating per Northern employed worker in (14). To break even, this must be compensated by a decline in $\bar{d}_{N}$, implying a decrease in $L_{N}^{Y}$ and thus an increase in $L_{N}^{I}$ and $x_{N}$. Therefore, the fourth effect contributes to a positive slope of the Northern steadystate curve. Figure 1 illustrates all four cases for the steady-state equilibrium. 
Panel (a) illustrates the case of an economy with a fairly flexible labor market (like the US), considered by DS (2007), with $\beta>\beta^{\text {crit }}$ and $B<B^{\text {crit }}$. The other three panels capture possible cases of economies with relative inflexible labor market institutions (like continental Western European countries), with either firing costs above the critical level (panels (b) and (d)) or labor market flexibility below the critical level (panels (c) and (d)). ${ }^{9}$

Given the steady-state solution $\left(x_{N}, C\right)$ at $\mathrm{E}_{0}$ and $I=n /(\lambda-1)$, all other variables are also determined. $L_{N}^{I} / L_{N}=I x_{N} / \eta_{I}$ follows for given $I$ and $x_{N}$, and $u$ is derived from (29) for given $I, C$, and $x_{N}$. For given $C$ and $u, L_{N}^{Y}$ is determined by (28). Since $L_{N}$ follows for given $\bar{L}_{N}$ and $u, L_{N}^{I}$ is also determined, as is the equilibrium path for $Q=x_{N} L_{N}$. Given $L_{N}, x_{N}, I$, and $C, \bar{d}_{N}$ is defined by (14) and $\bar{d}_{S}$ by (19). Global per-capita consumption expenditure $\bar{c}$ is found by noting first that $\int_{0}^{1} q(\omega, t) p(\omega, t)^{1-\sigma} d \omega=p_{N}^{1-\sigma} Q_{N}(t)+p_{S}^{1-\sigma} Q_{S}(t)$, which can be used together with (21) in (7) to derive

$$
\bar{d}_{N}=\frac{p_{N}^{-\sigma} \bar{c}(\lambda I+C)}{p_{N}^{1-\sigma} \lambda I+p_{S}^{1-\sigma} C}, \quad \bar{d}_{S}=\frac{p_{S}^{-\sigma} \bar{c}(\lambda I+C)}{p_{N}^{1-\sigma} \lambda I+p_{S}^{1-\sigma} C} .
$$

With $p_{N}=[\sigma /(\sigma-1)] w_{N}$ and $p_{S}=[\sigma /(\sigma-1)] w_{S}, \bar{d}_{N}\left(\right.$ or $\left.\bar{d}_{S}\right)$ and the wage rates determine $\bar{c}$, which then determines global consumption expenditure $E=\bar{c}\left(L_{N}+\bar{L}_{S}\right)$. As for $w_{N}$, it suffices to derive a constant relative wage $w_{N} / w_{S}$, given the normalization $w_{S} \equiv 1$. Dividing (14) by (19) and solving the resulting equation for $\bar{d}_{N} / \bar{d}_{S}$ gives the relative $R \& D$ condition

$$
\frac{\bar{d}_{N}}{\bar{d}_{S}}=\frac{\left(1-s_{R}\right) \eta_{C}[\rho+(1+B)(I+C)]}{\eta_{I}(\rho+I)}=\left(\frac{w_{S}}{w_{N}}\right)^{\sigma} .
$$

Here, the second equality follows because equation (7), its Southern equivalent, and the monopolists' markup pricing rule give $\bar{d}_{N} / \bar{d}_{S}=\left(p_{S} / p_{N}\right)^{\sigma}=\left(w_{S} / w_{N}\right)^{\sigma}$. Finally, the assumption $w_{N}>w_{S}>w_{N} / \lambda^{1 /(\sigma-1)}$ that is necessary for the postulated Vernon-type product cycle requires that

$$
1>\frac{w_{S}}{w_{N}}=\left\{\frac{\left(1-s_{R}\right) \eta_{C}[\rho+(1+B)(I+C)]}{\eta_{I}(\rho+I)}\right\}^{\frac{1}{\sigma}}>\lambda^{\frac{1}{1-\sigma}}
$$

is fulfilled. The Northern wage rate decreases with larger $B$ due to lower Northern R\&D benefits, which reduces labor demand in the North. For $I=n /(\lambda-1)$, it follows from (34) that $w_{N}>w_{S}$ imposes an upper bound for the firing costs parameter:

$$
B<\left[\frac{\eta_{I}(\rho+n /(\lambda-1))}{\left(1-s_{R}\right) \eta_{C}}-\rho\right] \frac{1}{n /(\lambda-1)+C}-1 \equiv B^{\max } .
$$

In addition, $w_{N}<\lambda^{1 /(\sigma-1)} \equiv w_{N}^{\max }$ must be fulfilled in (35) for the production location to shift back from the South to the North in the case of Northern innovation in an industry with a Southern quality leader. To ensure that all four types of steady-state equilibria of Figure 1 exist for feasible parameter values, Table A1 in the Appendix provides a numerical example for each case. Finally, as is derived in DS (2007), the common steady-state growth rate of both countries is

$$
\dot{z} / z=(\lambda-1) I /(\sigma-1)=n /(\sigma-1) .
$$




\section{Globalization}

Globalization (a rise in $\bar{L}_{S}$ ) requires an increase in $x_{N}$ for any given level of $C$ in the Southern steady-state condition (31) in order to restore R\&D and labor-market equilibrium in the South. This implies a shift of the corresponding curve to the right, as shown in Figure 2.

In the case of a flexible Northern labor market $\left(\beta>\beta^{\text {crit }}\right)$ with relatively low firing costs $\left(B<B^{\text {crit }}\right)$, globalization raises $x_{N}$ and $C$. Southern imitation increases because there is more labor available for doing R\&D. The rise in $x_{N} \equiv Q / L_{N}$ means that the growth rate of average product quality exceeds temporarily the steady-state level given by (20) and (25) as $\dot{Q} / Q=n$. This in turn implies that the Northern innovation rate temporarily exceeds the steady-state level $I=n /(\lambda-1)$, and R\&D employment must increase permanently in the North. These additional Northern R\&D workers come

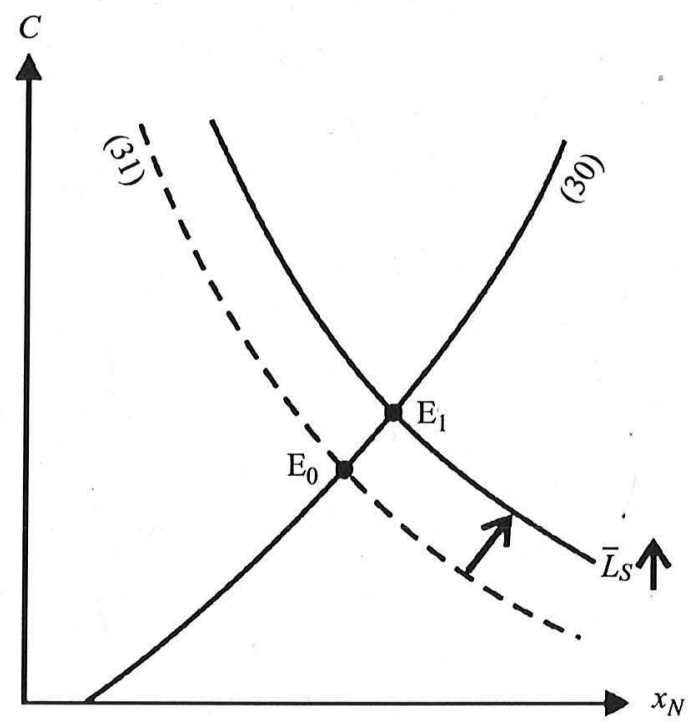

Panel (a): $B<B^{\text {crit }}$ and $\beta>\beta^{\text {crit }}$

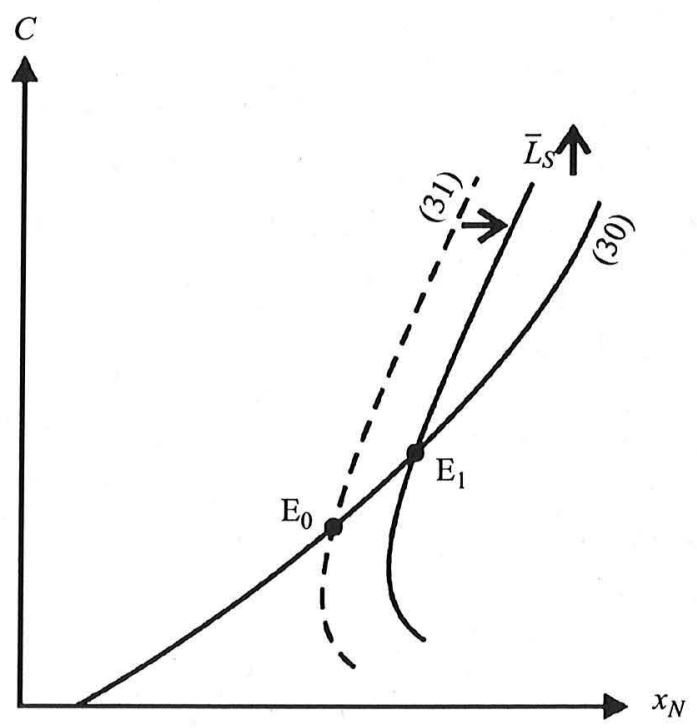

Panel (c): $B<B^{\text {crit }}$ and $\beta<\beta^{\text {crit }}$

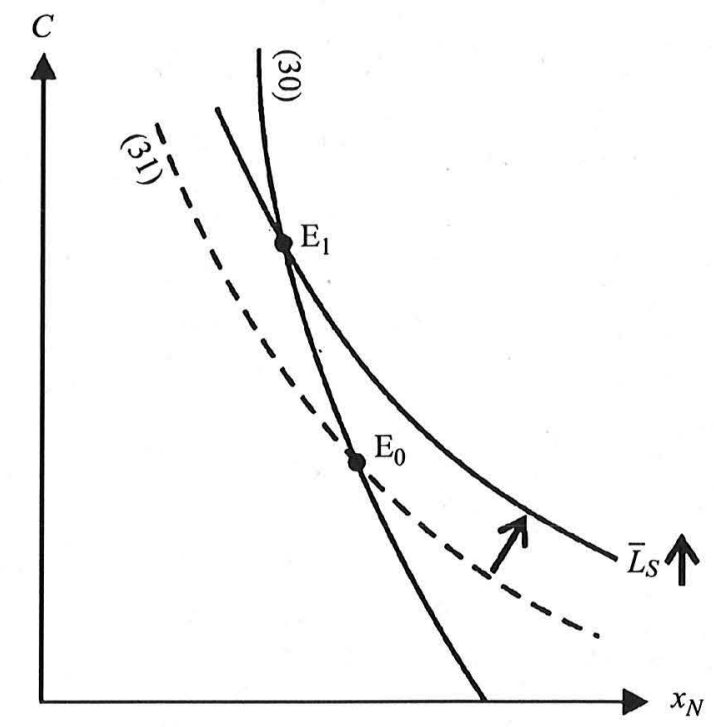

Panel (b): $B>B^{\text {crit }}$ and $\beta>\beta^{\text {crit }}$

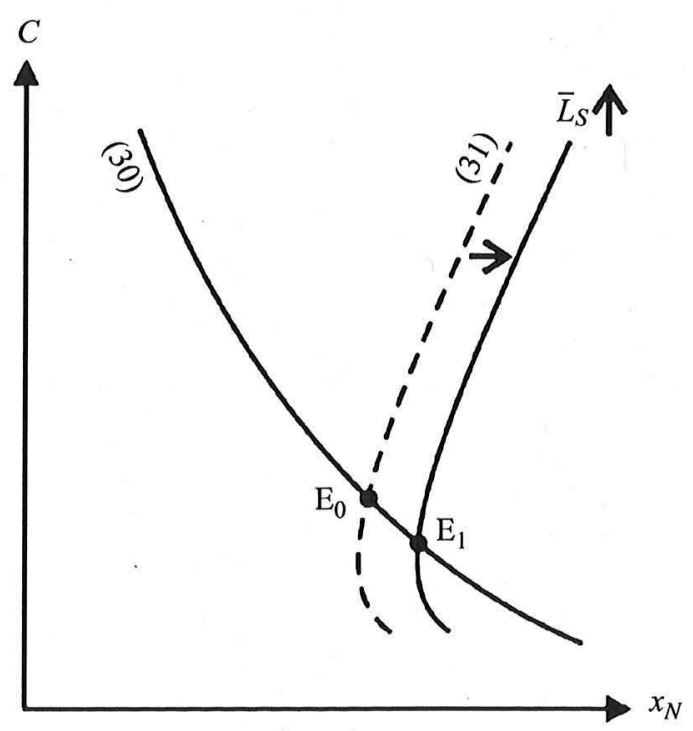

Panel (d): $B>B^{\text {crit }}$ and $\beta<\beta^{\text {crit }}$

Figure 2. Steady-State Effects of Globalization 
from the production sector, because rising Southern imitation leads to a decrease in the fraction $m_{N}=I /(I+C)$ of industries with a Northern quality leader. Hence, consumers of both countries benefit in terms of a temporary push of the quality-growth rate. However, Northern production workers suffer from increased unemployment according to (29).

The same results emerge in the case of an inflexible Northern labor market with relatively low firing costs $\left(\beta<\beta^{\text {crit }}\right.$ and $\left.B<B^{\text {crit }}\right)$ as depicted in panel (c) of Figure 2. Again, the increase in Southern copying implies that fewer Northern production workers are needed. In addition, because of the low job-finding rate, the increase in unemployment is particularly strong, which raises Northern and Southern R\&D benefits per Northern employed worker in (14) and (19), respectively. Moreover, Northern $\mathrm{R} \& \mathrm{D}$ becomes more profitable since $w_{N}$ decreases with rising $C$ for given $w_{S} \equiv 1$; see (34). Therefore, $x_{N}$ also increases in the case depicted in panel (c).

With $\beta>\beta^{\text {crit }}$ and $B>B^{\text {crit }}$, however, globalization leads to an increase in $C$ but a decrease in $x_{N}$, as shown in panel (b) of Figure 2. While the increase in $C$ comes, as before, from the simple fact that more Southern workers can do more $R \& D$, the decrease in $x_{N}$ reflects a net reallocation of Northern labor from R\&D to production despite the decrease in $w_{N}$. For large enough firing costs, the reduction in R\&D benefits from the expected costs of future dismissals more than outweighs the decrease in $\mathrm{R} \& \mathrm{D}$ costs from the lower $w_{N}$ and the increase in $\mathrm{R} \& \mathrm{D}$ benefits from the larger Southern market size. Hence, the North suffers from a temporary decline of the quality-growth rate. The net effect on Northern unemployment is ambiguous, which can be seen formally from (29), where a rise in $C$ and a decrease in $x_{N}$ have opposite effects on $u$.

With $\beta<\beta^{\text {crit }}$ and $B>B^{\text {crit }}$, globalization results in an increase in $x_{N}$ but a decrease in $C$, as is shown in panel (d) of Figure 2: more Southern labor resources produce less imitative R\&D in equilibrium! As in the case of panel (b), the negative slope of the Northern steady-state curve (30) shows the dominance of the "firing-cost effect" of a change in the Southern imitation rate explained before, which establishes a negative relationship between $C$ and $x_{N}$. Despite the high firing costs, globalization improves Northern innovation incentives because of the low job-finding rate $\beta$. Formally, the positive marginal impact of an increase in $\bar{L}_{S}$ on the R\&D benefits per Northern employed worker (right-hand side of (14)) is the larger the smaller Northern employment $L_{N}$ is, and $L_{N}$ is particularly small for $\beta<\beta^{\text {crit }}$. Hence, there is a temporary increase in the Northern innovation rate $I$ which raises permanently Northern R\&D employment $L_{N}^{I}$ and the relative R\&D difficulty $x_{N}$. Given $B>B^{\text {crit }}$, this is only compatible with a Northern steady-state equilibrium if the Southern imitation rate declines permanently, which implies a significant reduction in Northern expected firing costs and therefore supports Northern increased innovative R\&D expenditure. The relative Northern wage rate rises because of the decline in $C$. The resulting increase in the relative Northern goods price $p_{N} / p_{S}$ diverts consumer demand toward Southern goods, hence $\bar{d}_{S}$ increases and diverts Southern labor from R\&D to production. Northern unemployment unambiguously declines despite the opposite effects on $C$ and $x_{N}$ : while $C$ declines (lower unemployment risk for Northern production workers), $L_{N}^{Y}$ may rise since the proportion of industries $m_{N}=I /(I+C)$ producing in the North increases, or it may decline because of the rising R\&D-labor demand. Thus either both $L_{N}^{Y}$ and $L_{N}^{I}$ increase, and since $(1-u) \bar{L}_{N}=L_{N}^{Y}+L_{N}^{I}$, this requires a decrease in $u$, or if $L_{N}^{Y}$ in fact declines despite the increase in $m_{N}$, then the joint decrease in $L_{N}^{Y}$ and $C$ necessarily implies a decline in $u$; see (28). I summarize my findings in 
Proposition 1. Starting from a steady-state equilibrium with (35) being fulfilled, globalization (i.e. increased Southern trade integration, modeled as an increase in $\bar{L}_{S}$ ) results in

(i) a permanent increase in the rate of Southern copying $(C \uparrow)$, a permanent increase in relative $R \& D$ difficulty $\left(x_{N} \uparrow\right)$, a short-run increase in Northern innovation and the quality-growth rate $(I \uparrow, \dot{Q} / Q \uparrow)$ above their steady-state levels, no change in the long-run innovation rate $I=n /(\lambda-1)$, a permanent decrease in NorthSouth wage inequality $\left(w_{N} / w_{S} \downarrow\right)$, and an increase in the Northern unemployment rate $(u \uparrow)$, if $B<B^{\text {crit }}$, independent of the value for $\beta$;

(ii) a permanent increase in the rate of Southern copying $(C \uparrow)$, a permanent decrease in relative $R \& D$ difficulty $\left(x_{N} \downarrow\right)$, a short-run decrease in Northern innovation and the quality-growth rate $(I \downarrow, \dot{Q} / Q \downarrow)$ below their steady-state levels, no change in the long-run innovation rate $I=n /(\lambda-1)$, and a permanent decrease in NorthSouth wage inequality $\left(w_{N} / w_{S} \downarrow\right)$, while the net effect on Northern unemployment is ambiguous, if $\beta>\beta^{\text {crit }}$ and $B>B^{\text {crit; }}$

(iii) a permanent decrease in the rate of Southern copying $(C \downarrow)$, a permanent increase in relative $R \& D$ difficulty $\left(x_{N} \uparrow\right)$, a short-run increase in Northern innovation and the quality-growth rate $(I \uparrow, Q / Q \uparrow)$ above their steady-state levels, no change in the long-run innovation rate $I=n /(\lambda-1)$, a permanent increase in NorthSouth wage inequality $\left(w_{N} / w_{S} \uparrow\right)$, and a decrease in the Northern unemployment rate $(u \downarrow)$, if $\beta<\beta^{\text {crit }}$ and $B>B^{\text {crit }}$.

Hence workers in Northern economies with inflexible labor markets do not suffer more from increased Southern trade integration than in those with more flexible labor markets. In particular, Northern countries with large labor market adjustment costs for both firms and workers $\left(B>B^{\text {crit }}\right.$ and $\left.\beta<\beta^{\text {crit }}\right)$ enjoy a "double dividend" from this type of globalization: a permanent reduction of unemployment and a temporary acceleration of quality growth, which permanently raises the average quality level of consumption goods. This is not true for countries with either asymmetric (i.e. $B>B^{\text {crit }}$ and $\beta>\beta^{\text {crit }}$, or $B<B^{\text {crit }}$ and $\left.\beta<\beta^{\text {crit }}\right)$ or no significant $\left(B<B^{\text {crit }}\right.$ and $\left.\beta>\beta^{\text {crit }}\right)$ labor market adjustment costs. The reason for this result is that the Southern imitation rate decreases with globalization in the case of a very inflexible Northern labor market because of the resulting general-equilibrium feedback effects on Southern R\&D firms. This cannot happen in models like Arnold (2002) where the Southern imitation rate is exogenously fixed.

\section{Conclusions}

This paper emphasizes that the Southern "globalization threat" for the labor markets in advanced industrialized countries is determined in general equilibrium and is thus endogenous. In particular, the degree of Northern labor market frictions (firing costs, job-finding rate) determines both the size of the Southern imitation rate and the sign of the globalization effects on employment, growth, and wage rates. My results contradict the popular view that consumers in Northern countries with flexible labor markets will necessarily benefit most from "globalization" (increased Southern trade integration). For example, I show that only Northern countries with substantial labor market adjustment costs for both firms and workers enjoy a "double dividend" from globalization: a permanent reduction in unemployment and a temporary increase in the quality-growth rate of consumer goods.

I am anxious to point out that my results do not imply the recommendation that Northern labor markets should be made inflexible enough such that Northern 
economies are able to enjoy this double dividend from globalization. In this model, a decrease in the Northern job-finding rate or an increase in Northern firing costs could have harmful employment or growth effects, depending on the initial level of labor market frictions. The basic message is rather that there is no obvious reason to believe that Northern countries with particularly inflexible labor markets should fear the globalization "threat" more than others. Instead, globalization can help to mitigate their employment and growth problems which in turn may be caused by excessive labor market frictions. Importantly, these results are obtained in a model which analyzes a particular form of globalization and which assumes no kind of real-wage rigidity.

Further research could try to endogenize Northern labor market institutions within this type of dynamic North-South nonscale growth models by adding a politicaleconomy dimension. This could be fruitful since it appears to be an empirical regularity that employment protection and openness are positively correlated (Agell, 2002). As argued in this paper, the level of job protection (as captured by the firing costs) in open Northern economies is highly relevant for the qualitative effects of globalization shocks coming from the South.

\section{Appendix}

Table A1. Numerical Verification of Steady-State Equilibria ${ }^{\mathrm{a}}$

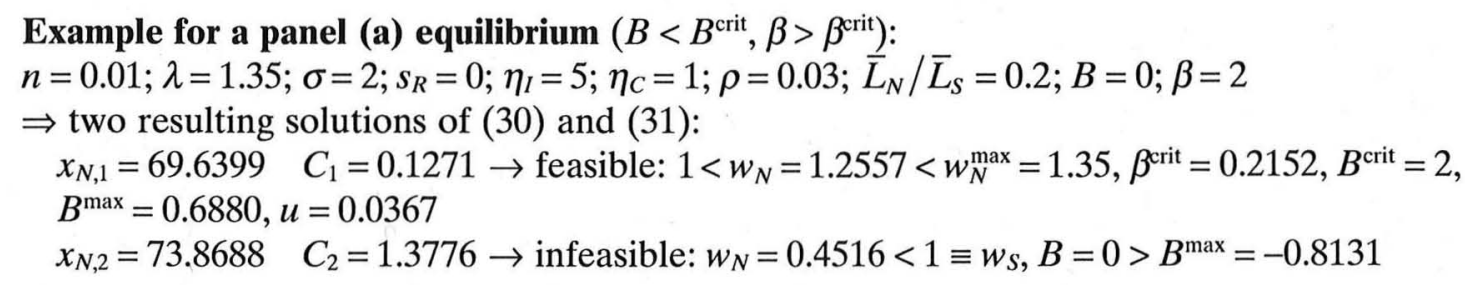

Example for a panel (b) equilibrium $\left(B>B^{\text {crit }}, \beta>\beta^{\text {crit }}\right)$ :

$n=0.01 ; \lambda=1.35 ; \sigma=1.5 ; s_{R}=0.2 ; \eta_{I}=10 ; \eta_{C}=1 ; \rho=0.02 ; \bar{L}_{N} / \bar{L}_{S}=0.2 ; B=2 ; \beta=2$

$\Rightarrow$ two resulting solutions of (30) and (31):

$x_{N, 1}=136.5622 \quad C_{1}=0.0561 \rightarrow$ feasible: $1<w_{N}=1.7001<w_{N}^{\max }=1.8225, \beta^{\text {crit }}=0.0415, B^{\text {crit }}=1$,

$B^{\max }=5.9379, u=0.0167$

$x_{N, 2}=133.7156 \quad C_{2}=2.1172 \rightarrow$ infeasible: $w_{N}=0.2068<1 \equiv w_{S}, B=2>B^{\max }=-0.7264$

Example for a panel (c) equilibrium $\left(B<B^{\text {crit }}, \beta<\beta^{\text {crit }}\right)$ :

$n=0.01 ; \lambda=1.42 ; \sigma=2.1 ; s_{R}=0.2 ; \eta_{I}=3.5 ; \eta_{C}=1 ; \rho=0.03 ; \bar{L}_{N} / \bar{L}_{S}=1 ; B=0.51 ; \beta=0.01$

$\Rightarrow$ two resulting solutions of (30) and (31):

$x_{N, 1}=46.7872 C_{1}=0.0392 \rightarrow$ feasible: $1<w_{N}=1.3510<w_{N}^{\max }=1.3754, \beta^{\text {crit }}=0.0173, B^{\text {crit }}=2$,

$B^{\max }=2.2596, u=0.5720$

$x_{N, 2}=46.3380 \quad C_{2}=0.0314 \rightarrow$ infeasible: $w_{N}=1.4160>w_{N}^{\max }=1.3754$

Example for a panel (d) equilibrium $\left(B>B^{\text {crit }}, \beta<\beta^{\text {crit }}\right)$ :

$n=0.038 ; \lambda=1.42 ; \sigma=2.1 ; s_{R}=0.046 ; \eta_{I}=5 ; \eta_{C}=1 ; \rho=0.04 ; \bar{L}_{N} / \bar{L}_{S}=0.88 ; B=0.6 ; \beta=0.05$

$\Rightarrow$ two resulting solutions of (30) and (31):

$x_{N, 1}=16.8950 \quad C_{1}=0.1452 \rightarrow$ feasible: $1<w_{N}=1.2655<w_{N}^{\max }=1.3754, \beta^{\text {crit }}=0.0816$,

$B^{\text {crit }}=0.0526, B^{\max }=1.7320, u=0.5339$

$x_{N, 2}=17.0034 \quad C_{2}=0.1027 \rightarrow$ infeasible: $w_{N}=1.3775>w_{N}^{\max }=1.3754$

Note:

a The parameters chosen are well within standard ranges given and motivated in the recent literature; see DS (1999, p. 467), Glass and Saggi (2002, p. 403), Lundborg and Segerstrom (2002, pp. 190-91), Şener (2006, p. 793), and Segerstrom (2007, p. 272). 


\section{References}

Agell, Jonas, "On the Determinants of Labour Market Institutions: Rent Seeking vs. Social Insurance," German Economic Review 3 (2002):107-35.

Angrist, Joshua D. and Adriana D. Kugler, "Protective or Counter-Productive? Labour Market Institutions and the Effects of Immigration on EU Natives," Economic Journal 113 (2003):F302-31.

Arnold, Lutz G., "On the Growth-Effects of North-South Trade: The Role of Labor Market Flexibility," Journal of International Economics 58 (2002):451-66.

Blanchard, Olivier and Pedro Portugal, "What Hides Behind an Unemployment Rate: Comparing Portuguese and U.S. Labor Markets," American Economic Review 91 (2001):187-207.

Dinopoulos, Elias and Paul S. Segerstrom, "A Schumpeterian Model of Protection and Relative Wages," American Economic Review 89 (1999):450-72.

— "North-South Trade and Economic Growth," manuscript, University of Florida and Stockholm School of Economics (2007).

Glass, Amy J. and Kamal Saggi, "Intellectual Property Rights and Foreign Direct Investment," Journal of International Economics 56 (2002):387-410.

Grieben, Wolf-Heimo and Fuat Şener, "Globalization, Rent Protection Institutions, and Going Alone in Freeing Trade," manuscript, University of Konstanz and Union College, Schenectady (2008).

Grossman, Gene M. and Elhanan Helpman, "Quality Ladders and Product Cycles," Quarterly Journal of Economics 106 (1991):557-86.

Helpman, Elhanan, "Innovation, Imitation, and Intellectual Property Rights," Econometrica 61 (1993):1247-80.

Helpman, Elhanan and Oleg Itskhoki, "Labor Market Rigidities, Trade and Unemployment," manuscript, Harvard University (2008).

Kenen, Peter B., The International Economy, 4th edn, Cambridge: Cambridge University Press (2000).

Lu, Chia-Hui, "Moving Up or Moving Out? A Unified Theory of R\&D, FDI, and Trade," Journal of International Economics 71 (2007):324-43.

Lundborg, Per and Paul S. Segerstrom, "The Growth and Welfare Effects of International Mass Migration," Journal of International Economics 56 (2002):177-204.

Schmidt, Christoph M., Anette Stilz, and Klaus F. Zimmermann, "Mass Migration, Unions, and Government Intervention," Journal of Public Economics 55 (1994):185-201.

Segerstrom, Paul S., "Intel Economics," International Economic Review 48 (2007):247-80.

Şener, Fuat, "Schumpeterian Unemployment, Trade and Wages," Journal of International Economics 54 (2001):119-48.

- "Labor Market Rigidities and R\&D-Based Growth in the Global Economy," Journal of Economic Dynamics and Control 30 (2006):769-805.

Sinn, Hans-Werner, "The Dilemma of Globalisation: A German Perspective," Économie Internationale 100 (2004):111-20.

\section{Notes}

1. Angrist and Kugler (2003) provide evidence on the negative employment effects (aggravated by labor and product market rigidities) of non-EU immigration to EU countries. Helpman and Itskhoki (2008) show in a two-country trade model with firm heterogeneity, search and matching in the labor market, wage bargaining, firing costs, and unemployment benefits that the country with lower labor market frictions gains proportionately more from trade liberalization than the other country with higher labor market frictions. The model of Arnold (2002) is discussed further below.

2. This exercise follows Dinopoulos and Segerstrom (2007), Lu (2007), and Grieben and Şener (2008). The latter also provides some evidence on increased Southern trade integration.

3. With respect to the main result of this paper, similar in spirit is the finding of Schmidt et al. (1994): in their static model with skilled and unskilled domestic labor, it is precisely the labor 
market inflexibility introduced by a monopoly union determining wage rates which opens up the possibility for low-skilled immigration (another facet of globalization) to raise domestic employment and output.

4. Arnold (2002) generalizes the North-South product-cycle model of Helpman (1993) in order to analyze the effects of rising Southern imitation on Northern growth and unemployment. In particular, he focuses on how these effects depend on the degree of Northern labor market flexibility, as measured by a unified job-finding rate. He finds that for a high (low) degree of labor market flexibility, rising Southern imitation stimulates (impedes) Northern growth. Furthermore, whenever rising Southern imitation reduces Northern growth, it also raises Northern unemployment.

5. Note that Northern unemployed workers do not generate a positive demand since I abstract from unemployment benefits for simplicity.

6. Firing costs may contain redundancy payments to the workers (as well as other administrative costs associated with layoffs).

7. A microeconomically founded version of frictional unemployment within a neoSchumpeterian growth model with matching on the labor market is developed by Şener (2001). The simpler version used here is more tractable without changing any of the results qualitatively. There is empirical evidence that the job-finding rate $\beta$ is affected by firing costs; see Blanchard and Portugal (2001). However, to disregard this possible interaction allows me to separate clearly the (asymmetric) impacts of both types of labor market frictions in the later analysis of globalization effects.

8. Ceteris paribus, the Northern unemployment rate rises with a larger $\sigma$ since $p_{N}$ decreases with a higher $\sigma$, which raises demand for Northern products and thus increases production employment vulnerable to Southern imitation. A higher $B$, a lower $s_{R}$, or a lower $\eta_{I}$ increase Northern $R \& D$ costs relative to $R \& D$ benefits, which also tends to raise Northern production employment relative to R\&D employment. Finally, a lower $n$ increases $u$ due to the assumption that all newly-born individuals immediately find a job.

9. An increase in $B$ rotates the Northern steady-state curve (30) counterclockwise. In panel (b) of Figure 1, I consider only the case of a $B>B^{\text {crit }}$ such that this curve is steeper in absolute value than the Southern steady-state curve (31). Similarly, a decrease in $\beta$ rotates the Southern steadystate curve clockwise, and in panel (c) I only consider the case where $\beta<\beta^{\text {crit }}$ is such that the slope

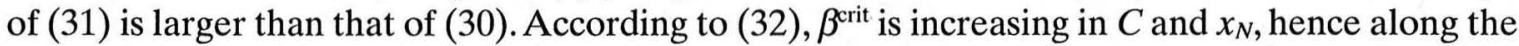
curve for (31) toward lower values for $C$ and $x_{N}$ in panels (c) and (d), $\beta^{\text {crit }}$ is declining and will eventually fall below any given value for $\beta$, which explains the change in slope of (31) for low enough values of $C$ and $x_{N}$ at the point of intersection with the $\left(\beta=\beta^{\text {crit }}\right)$-curve. Thus, the assumption $\beta<\beta^{\text {crit }}$ in panels (c) and (d) refers to a steady-state equilibrium on the positively sloped segment of the curve for (31) located above the $\left(\beta=\beta^{\text {crit }}\right)$-curve. 